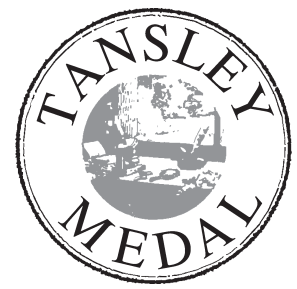

\title{
Testing hypotheses that link wood anatomy to cavitation resistance and hydraulic conductivity in the genus Acer
}

\author{
Frederic Lens ${ }^{1,5}$, John S. Sperry ${ }^{2}$, Mairgareth A. Christman ${ }^{2}$, Brendan Choat ${ }^{3}$, David Rabaey ${ }^{1}$ and Steven Jansen ${ }^{4}$ \\ ${ }^{1}$ Laboratory of Plant Systematics, Institute of Botany and Microbiology, Kasteelpark Arenberg 31 Box 2437, K.U. Leuven, BE-3001 Leuven, Belgium; ${ }^{2}$ Biology \\ Department, University of Utah, 257 1400E Salt Lake City, UT 84112, USA; ${ }^{3}$ Plant Science Division, Research School of Biology, The Australian National \\ University, Canberra, ACT, 0200, Australia; ${ }^{4}$ Institute for Systematic Botany and Ecology, Ulm University, Albert Einstein Allee 11, D-89081, Ulm, Germany; \\ ${ }^{5}$ Present address: Netherlands Centre for Biodiversity Naturalis (section NHN), Leiden University, PO Box 9514, NL-2300 RA, Leiden, the Netherlands
}

Author for correspondence:

Frederic Lens

Tel: +3216328637

Email: lens@nhn.leidenuniv.nI

Received: 19 August 2010

Accepted: 17 September 2010

New Phytologist (2011) 190: 709-723

doi: $10.1111 /$ j.1469-8137.2010.03518.x

Key words: Acer, cavitation resistance, hydraulic conductivity, pit structure, rare pit hypothesis, vessel distribution, vessel wall thickenings, wood density.

\section{Summary}

- Vulnerability to cavitation and conductive efficiency depend on xylem anatomy. We tested a large range of structure-function hypotheses, some for the first time, within a single genus to minimize phylogenetic 'noise' and maximize detection of functionally relevant variation.

- This integrative study combined in-depth anatomical observations using light, scanning and transmission electron microscopy of seven Acer taxa, and compared these observations with empirical measures of xylem hydraulics.

- Our results reveal a $2 \mathrm{MPa}$ range in species' mean cavitation pressure (MCP). MCP was strongly correlated with intervessel pit structure (membrane thickness and porosity, chamber depth), weakly correlated with pit number per vessel, and not related to pit area per vessel. At the tissue level, there was a strong correlation between MCP and mechanical strength parameters, and some of the first evidence is provided for the functional significance of vessel grouping and thickenings on inner vessel walls. In addition, a strong trade-off was observed between xylemspecific conductivity and MCP. Vessel length and intervessel wall characteristics were implicated in this safety-efficiency trade-off.

- Cavitation resistance and hydraulic conductivity in Acer appear to be controlled by a very complex interaction between tissue, vessel network and pit characteristics.

\section{Introduction}

Xylem cavitation represents an important constraint on plant survival, and xylem hydraulic conductance potentially limits plant productivity (Rood et al., 2000; McDowell et al., 2008; Brodribb \& Cochard, 2009). Numerous experimental studies on xylem hydraulics in woody plants have been published, and there is a rich literature on ecological wood anatomy that has fostered numerous hypothetical correlations between wood structure and its hydraulic function.

Frederic Lens was awarded the 2010 New Phytologist Tansley Medal for excellence in plant science. The medal is in recognition of Frederic's outstanding contribution to research in plant science, at an early stage in his career, as presented in this article; see the Editorial by Woodward \& Hetherington, 190: 509.
However, the few integrative studies that have combined anatomical and experimental approaches mostly lack indepth anatomical observations using electron microscopy (Wheeler et al., 2005; Sperry et al., 2006; Cochard et al., 2008; but see Hacke \& Jansen, 2009; Pittermann et al., 2010). The present study bridges the structure-function gap by combining transmission electron microscope (TEM), scanning electron microscope (SEM), and light microscope (LM) observations of seven Acer species with empirical measures of xylem hydraulics. By studying closely related species in a single genus, we reduced phylogenetic noise in anatomical traits. This facilitated the testing of a wide range of structure-function hypotheses, some of which have not been evaluated before.

The experimental literature implicates intervessel pitting as a key structure determining both hydraulic conductivity 
and cavitation resistance. The flow resistance through intervessel pits accounts for $>50 \%$ of the total resistance of the vessel network (Wheeler et al., 2005; Choat et al., 2008). Vulnerability to cavitation of air-seeding is determined by the ability of the pitted intervessel walls to resist the passage through an air-water interface (Zimmermann, 1983). Since air-seeding requires the failure of only one intervessel pit, all else being equal, the more extensive the pitting, the greater should be the probability of one pit failing ('rare pit' hypothesis; Wheeler et al., 2005; Christman et al., 2009). All else is not necessarily equal, however, and the seemingly inevitable effect of pit quantity can be compensated for by changes in pit structure (Sperry et al., 2007).

Recently, a comparative study of three Acer species concluded that the major determinant of cavitation resistance was established by differences in pit structure rather than pit quantity (Christman et al., 2009). However, this study did not examine the ultrastructure of the intervessel pits, and pit quantity was expressed as pit area per vessel $\left(A_{\mathrm{p}}\right)$ rather than pit number $\left(N_{\mathrm{p}}\right)$. One of the hypotheses we tested in the present paper was to evaluate whether pit structure (especially pit membrane thickness and porosity, and pit chamber depth) is more crucial than pit quantity per vessel (whether measured as $A_{\mathrm{p}}$ or $N_{\mathrm{p}}$ ) for explaining differences in cavitation resistance between Acer species.

Other hypotheses are related to the mechanical strength of the vessel walls and surrounding fibres. Cavitation-resistant xylem is likely to carry water under more negative pressures. These stronger tensions put a greater mechanical load on the vessel walls, which need to be well reinforced to avoid collapse (Hacke et al., 2001). The pressure at which implosion of the vessel occurs is a function of the 'thicknessto-span' ratio, that is, the double vessel wall thickness per lumen diameter $\left(T_{\mathrm{w}} D_{\mathrm{v}}^{-1}\right)$. Wood density (WD) is also strongly influenced by thickness-to-span ratio of the imperforate tracheary elements (Hacke et al., 2001; MartínezCabrera et al., 2009). Because both $T_{\mathrm{w}} D_{\mathrm{v}}^{-1}$ and WD increase with cavitation resistance in many broad-scale studies (Hacke et al., 2001; Jacobsen et al., 2005, 2007; Chave et al., 2009; Onoda et al., 2009), we investigated whether these two mechanical parameters are also significant at the genus level.

The ecological wood anatomical literature has produced a number of correlational hypotheses between wood anatomy and function, but many of these have not been well evaluated experimentally. More cavitation-resistant species are thought to possess shorter vessel elements $\left(L_{\mathrm{e}}\right.$; Carlquist, 1966, 1975; Baas et al., 1983; Lens et al., 2003, 2004, 2009), lower vulnerability indices (VI $=$ vessel diameter divided by vessel frequency; Carlquist, 1975), lower mesomorphy indices $\left(\mathrm{MI}=\mathrm{VI} \times L_{\mathrm{e}}\right.$; Carlquist \& DeBuhr, 1977), and more pronounced thickenings on inner vessel walls (Carlquist, 1966). In addition, when vessels are embedded in a background of nonconductive fibres and not surrounded by abundant vasicentric tracheids, such as in
Acer, xeric-adapted species are hypothesized to have more and larger vessel multiples than more vulnerable species (Carlquist, 1984, 2009; Rosell et al., 2007).

A major hypothesis emerging from previous work is that small conduits are more resistant to cavitation than large ones (Ellmore \& Ewers, 1985; Hargrave et al., 1994; Cai \& Tyree, 2010), resulting in a trade-off between safe xylem (small conduits) and efficient xylem (large conduits). However, experimental support for such a safety vs efficiency correlation is often equivocal and statistically noisy for drought-induced cavitation (Wheeler et al., 2005; Hacke et al., 2006). If drought-induced cavitation resistance is influenced by the extent of intervessel pitting per vessel, larger vessels would, on average, be more vulnerable than smaller ones in the same vessel group. However, if cavitation is mostly influenced by intervessel pit structure, large vessels could be as safe from air-seeding as smaller ones regardless of how much pitting is present.

Acer species have been regularly included in experimental studies; for example, some of the first experimental evidence for air-seeding comes from Acer saccharum (Sperry \& Tyree, 1988). Also the wood anatomy of Acer has been extensively described (e.g. Yamauchi, 1962; Ogata, 1967), but integrative anatomical-physiological work is lacking. We combined detailed anatomical observations at the tissue level (i.e. the three-dimensional hydraulic network) and intervessel pit level with empirical measures on xylem hydraulics for seven Acer species. Our major focus was to evaluate previously published anatomical hypotheses with respect to cavitation resistance and conducting efficiency, and to reveal traits implicated in any trade-off we might observe between safety and efficiency within the genus.

\section{Materials and Methods}

\section{Plant material}

Branches c. $1 \mathrm{~m}$ in length and $8-11 \mathrm{~mm}$ in diameter belonging to different parts of an individual's crown were sampled around midday for a total of seven Acer taxa during the months of May-June 2009. Stems were wrapped tightly in plastic and stored in a cold room in the laboratory until use (up to $1 \mathrm{wk}$ ). Acer pseudoplatanus L. and Acer platanoides L. were irrigated street trees growing in Salt Lake City (UT, USA, c. $\left.40^{\circ} 45^{\prime} \mathrm{N} 111^{\circ} 51^{\prime} \mathrm{W}\right)$, A. saccharinum $\mathrm{L}$. was collected along the Jordan River near Salt Lake City (UT, USA, c. $\left.40^{\circ} 41^{\prime} 27^{\prime \prime} \mathrm{N} 111^{\circ} 5524^{\prime \prime} \mathrm{W}\right)$, and Acer glabrum Torr. var. diffusum (Greene) Smiley was collected in a narrow, shaded canyon in the arid House Range mountains (Sawtooth Canyon, UT, USA, c. $39^{\circ} 07^{\prime} \mathrm{N} 113^{\circ} 23^{\prime} \mathrm{W}$ ). Stems of the three remaining taxa were recollected from the same populations used by Christman et al. (2009). Voucher specimens are housed in the University of Utah (Salt Lake City). 
Vulnerability curves, mean cavitation pressure (MCP), and xylem-specific conductivity $\left(K_{x_{a}}\right)$

The standard centrifuge method (Li et al., 2008) was used to obtain vulnerability curves for $A$. glabrum var. diffusum, A. platanoides, A. pseudoplatanus and A. saccharinum. Six stems (not flushed) per species were trimmed under water to $14.1 \mathrm{~cm}$ length. The native conductivity measurements were made using $20 \mathrm{mmol} \mathrm{KCl}$ and a pressure head of c. 4-6 kPa (Alder $e$ al., 1997), and conductivity was expressed per stem area $\left(K_{\mathrm{Sa}}\right)$ and per xylem area $\left(K_{\mathrm{Xa}}\right.$; Table 1$)$. Stems were then spun in a Sorvall RC-5C centrifuge (Thermo Fisher Scientific, Waltham, MA, USA) at increasing speed until $>95 \%$ loss of conductivity was detected. The mean of the distribution of incremental conductivity loss with xylem pressure is the MCP. It was calculated for each stem from a Weibull curve fitted to the cumulative loss of conductivity measured by the vulnerability curve. The species MCP was calculated as the mean of the stem means. MCP is arguably better than the $50 \%$ loss of conductivity pressure (P50) for representing a species' cavitation resistance, especially if the curve is not symmetrical. We also report P50 values for comparison with their wide use in the literature (Table 4).

Conductivities and MCPs for A. glabrum var. glabrum, A. grandidentatum, and Acer negundo were taken from Christman et al. (2009) using the 'spin' method. Standard and spin methods have been shown to be statistically identical for the rotors used in our study ( $\mathrm{Li}$ et al., 2008). For short-vesseled species such as Acer (mean vessel lengths are $>$ four times shorter than the spinning stem segment, Table 3), numerous studies have validated centrifuge methods via comparisons with bench-top dehydration, native embolism, and air-injection experiments (Pockman et al., 1995; Alder et al., 1997; Cochard et al., 2005; Li et al., 2008). Although stems were flushed in the Christman et al. (2009) study, their vulnerability curves indicated minimal native embolism would be expected (as has been confirmed for two of the three species; Taneda \& Sperry, 2008; U. Hacke \& J. S. Sperry, unpublished).

\section{Light microscopy (LM)}

Transverse, tangential and radial sections of $20 \mu \mathrm{m}$ thickness were cut using a sledge microtome (Reichert, Vienna, Austria). After bleaching and rinsing with water, the sections were stained for $15 \mathrm{~s}$ with a $1: 2$ mixture of safranin $(0.5 \%$ in $50 \%$ ethanol) and alcian blue (1\% in water), dehydrated in an ethanol series $(50 \%, 75 \%, 96 \%)$, treated with a Parasolve clearing agent (Prosan, Merelbeke, Belgium), and mounted in Euparal (Agar Scientific, Stansted, UK) (Lens et al., 2005). Sections were observed using a Dialux 20 light microscope (Leitz, Wetzlar, Germany) and photographed with a PixeLINK digital camera (Ottawa, ON, Canada).
Table 1 List with major variables with definition and units employed

\begin{tabular}{|c|c|c|}
\hline Symbol & Definition & $\begin{array}{l}\text { Units } \\
\text { employed }\end{array}$ \\
\hline$A_{p}$ & $\begin{array}{l}\text { Average intervessel pit area per } \\
\text { vessel }=F_{\mathrm{p}} A_{v}\end{array}$ & $\mathrm{~mm}^{2}$ \\
\hline$A_{\mathrm{v}}$ & Average vessel wall area $=\pi D_{v} L_{v}{ }^{*}$ & $\mathrm{~mm}^{2}$ \\
\hline$A P_{f}$ & $\begin{array}{l}\text { Aperture shape }=\text { ratio of longest axis of } \\
\text { outer pit aperture over shortest axis }\end{array}$ & - \\
\hline$D_{\mathrm{m}}$ & Horizontal pit membrane diameter & $\mu \mathrm{m}$ \\
\hline$D_{\mathrm{p}}$ & Diameter of pit membrane pore & $\mathrm{nm}$ \\
\hline$D_{\mathrm{v}}$ & $\begin{array}{l}\text { Vessel diameter corresponding to } \\
\text { average lumen conductivity determined } \\
\text { from the Hagen-Poiseuille equation }\end{array}$ & $\mu \mathrm{m}$ \\
\hline$F_{\mathrm{ap}}$ & $\begin{array}{l}\text { Aperture fraction = pit aperture area per } \\
\text { pit membrane area }\end{array}$ & - \\
\hline$F_{\mathrm{c}}$ & $\begin{array}{l}\text { Contact fraction = fraction of the total } \\
\text { vessel wall perimeter in contact with } \\
\text { another vessel }\end{array}$ & - \\
\hline$F_{\mathrm{p}}$ & $\begin{array}{l}\text { Pit fraction }=\text { fraction of vessel wall area } \\
\text { occupied by intervessel } \\
\text { pits }=A_{\mathrm{p}} A_{\mathrm{v}}^{-1}=F_{\mathrm{c}} F_{\mathrm{pf}}\end{array}$ & - \\
\hline$F_{\mathrm{pf}}$ & $\begin{array}{l}\text { Pit-field fraction }=\text { fraction of intervessel } \\
\text { wall surface occupied by pits }\end{array}$ & - \\
\hline $\mathrm{Gl}$ & $\begin{array}{l}\text { Vessel grouping index = total number of } \\
\text { vessels divided by total number of vessel } \\
\text { groups; a solitary vessel counts as one } \\
\text { vessel group }\end{array}$ & - \\
\hline$K_{\mathrm{Sa}}$ & $\begin{array}{l}\text { Hydraulic conductivity per stem } \\
\text { cross-sectional area }\end{array}$ & $\begin{array}{l}\mathrm{mg} \mathrm{s}^{-1} \\
\mathrm{kPa}^{-1} \mathrm{~mm}^{-1}\end{array}$ \\
\hline$K_{\mathrm{Xa}}$ & $\begin{array}{l}\text { Hydraulic conductivity per xylem } \\
\text { cross-sectional area }\end{array}$ & $\begin{array}{l}\mathrm{mg} \mathrm{s}^{-1} \\
\mathrm{kPa}^{-1} \mathrm{~mm}^{-1}\end{array}$ \\
\hline$L_{\mathrm{e}}$ & Vessel element length & $\mu \mathrm{m}$ \\
\hline$L_{f}$ & Fiber length & $\mu \mathrm{m}$ \\
\hline$L_{\mathrm{t}}$ & $\begin{array}{l}\text { Thickness (width) of sculpturing on inner } \\
\text { vessel wall }\end{array}$ & $\mu \mathrm{m}$ \\
\hline$L_{p}$ & $\begin{array}{l}\text { Depth of pit chamber from membrane } \\
\text { surface to inner edge of pit aperture }\end{array}$ & $\mathrm{nm}$ \\
\hline$L_{v}$ & Vessel length & $\mathrm{m}$ \\
\hline$L_{v}^{*}$ & Log-transformed vessel length & $\mathrm{m}$ \\
\hline MCP & $\begin{array}{l}\text { Mean cavitation pressure from Weibull } \\
\text { function fits to vulnerability curves }\end{array}$ & $\mathrm{MPa}$ \\
\hline MI & Mesomorphy index $=\mathrm{VI} \times L_{\mathrm{e}}$ & - \\
\hline$N_{\mathrm{p}}$ & $\begin{array}{l}\text { Average pit number per } \\
\text { vessel }=4 A_{p}\left(\pi D_{m}^{2}\right)^{-1}\end{array}$ & - \\
\hline$P_{\mathrm{a}}$ & Air-seeding pressure & $\mathrm{MPa}$ \\
\hline$T_{\mathrm{m}}$ & Thickness of intervessel pit membrane & $\mathrm{nm}$ \\
\hline$T_{\mathrm{w}}$ & $\begin{array}{l}\text { Double thickness of vessel wall making } \\
\text { contact with an adjacent vessel }\end{array}$ & $\mu \mathrm{m}$ \\
\hline$T L^{-1}$ & $\begin{array}{l}\text { Number of thickenings on inner vessel } \\
\text { wall per axial vessel length }\end{array}$ & $100 \mu \mathrm{m}^{-1}$ \\
\hline$T_{\mathrm{w}} D_{\mathrm{v}}^{-1}$ & $\begin{array}{l}\text { Thickness-to-span ratio of } \\
\text { vessels = intervessel wall thickness } \\
\text { divided by vessel lumen diameter }\end{array}$ & - \\
\hline$V A_{x}^{-1}$ & $\begin{array}{l}\text { Vessel frequency = number of vessels } \\
\text { per wood area }\end{array}$ & $\mathrm{mm}^{-2}$ \\
\hline $\mathrm{VI}$ & Vulnerability index $=D_{v}\left(V A_{x}^{-1}\right)^{-1}$ & - \\
\hline WD & $\begin{array}{l}\text { Wood density, calculated as oven-dry } \\
\text { mass divided by air-dry volume at } \\
12-15 \% \text { moisture content }\end{array}$ & $\mathrm{g} \mathrm{cm}^{-3}$ \\
\hline
\end{tabular}

Some auto-correlated variables and generally nonsignificant ones do not appear in Figs 2, 6 and 7. 
Transverse sections were used to measure vessel density $\left(V A_{\mathrm{x}}^{-1}\right)$, vessel grouping index (GI, ratio of total number of vessels to total number of vessel groupings (incl. solitary and grouped vessels); Carlquist, 2001), and VI (vessel diameter divided by vessel frequency, Table 1) (Carlquist, 1975). Vessel diameters were measured as the diameter of a circle with the same area as the vessel lumen. Because lumen conductivity increases with diameter to the fourth power, we report the vessel diameter that corresponds to the average lumen conductivity $\left(D_{\mathrm{v}}=\left(\Sigma\left(D^{4} / n\right)\right)^{1 / 4} ;\right.$ lumen conductivity determined from the Hagen-Poiseuille equation). Thickness-to-span ratio $\left(T_{\mathrm{w}} D_{\mathrm{v}}^{-1}\right)$ was measured on vessels within $5 \%$ of $D_{\mathrm{v}}$ (Hacke et al., 2001). Double thickness of the vessel wall was also reported separately $\left(T_{\mathrm{w}}\right)$. The fraction of vessel surface area in contact with other vessels (contact fraction, $F_{\mathrm{c}}$ ) was estimated as the fraction of the total vessel wall perimeter that was in contact with another vessel. All parameters were averaged for complete radial sectors of current-year growth rings, based on two radial sectors per stem and five stems per species.

Longitudinal sections were used to measure intervessel pit-field fraction $\left(F_{\mathrm{pf}}=\right.$ pit area per intervessel wall area). Vessel element length $\left(L_{\mathrm{e}}\right)$ and fibre lengths $\left(L_{\mathrm{f}}\right)$ were determined from counts of 50 macerated cells (Franklin, 1945), taken from the outer part of the stem.

\section{Vessel length distributions}

The silicon injection method was used to obtain vessel length distributions (Hacke et al., 2007; Christman et al., 2009). The silicone was injected basipetally down the main stem from the base of the current year's extension growth. Five stems per species were flushed with $20 \mathrm{~mm} \mathrm{KCl}$ at $c$. $70 \mathrm{kPa}$ to remove reversible embolism and injected under 50-75 kPa pressure overnight with a $10: 1$ silicone : hardener mix (RTV-141; Rhodia, Cranbury, NJ, USA). A fluorescent optical brightener (Ciba Uvitex OB; Ciba Specialty Chemicals, Tarrytown, NY, USA) was mixed with chloroform $(1 \% \mathrm{w} / \mathrm{w})$ and added to the silicone (one drop $\mathrm{g}^{-1}$ ) to enable detection of silicone-filled vessels in stem sections under fluorescent microscopy. After allowing the silicone to harden for $2-3 \mathrm{~d}$, stems were sectioned at five positions beginning $6 \mathrm{~mm}$ from the injection end and ending 8 $12 \mathrm{~cm}$ back from the cut end. The fraction of silicone-filled vessels at each length was counted and the data analyzed for vessel length distribution as explained in Christman et al. (2009). Vessel length distributions are short-skewed, and therefore we report both the untransformed mean $\left(L_{\mathrm{v}}\right)$ and $\log$-transformed mean $\left(L_{\mathrm{v}}{ }^{*}\right)$.

\section{Calculation of intervessel pit area per vessel $\left(A_{p}\right)$ and pit number $\left(N_{p}\right)$ per vessel}

Average intervessel pit area per vessel $\left(A_{\mathrm{p}}\right)$ was obtained by methods detailed in Sperry et al. (2007). Briefly, the pit-field fraction $\left(F_{\mathrm{pf}}\right)$ was multiplied by the contact fraction $\left(F_{\mathrm{c}}\right)$ to give the fraction of vessel wall area occupied by intervessel pits ( $F_{\mathrm{p}}$, pit fraction). The pit fraction in turn was multiplied by the average vessel wall area $\left(A_{\mathrm{v}}=\pi D_{\mathrm{v}} L_{\mathrm{v}}{ }^{*}\right)$ to give $A_{\mathrm{p}}$. An estimate of the average $N_{\mathrm{p}}$ was obtained by dividing $A_{\mathrm{p}}$ by the average pit membrane area $\left(\pi D_{\mathrm{m}}{ }^{2} / 4\right)$.

\section{Wood density}

All values are reported as basic specific gravity (oven dry mass/ air dry volume at $12-15 \%$ moisture content/density of water), called wood density in the main text for simplicity. Measurements were performed on five dried wood samples (without pith and bark) per species using the water displacement method (Chave et al., 2006). A container filled with water was placed on a digital balance (precision $0.01 \mathrm{~g}$; Acculab Vicon, Sartorius, Göttingen, Germany). The airdried wood specimens were carefully forced under water with a needle, such that it does not contact the sides or bottom of the container. The measured mass of displaced water equals the dried volume of the wood specimen. Oven-dry mass was measured on the same sample by drying it in an oven at $60^{\circ} \mathrm{C}$ until it achieved constant mass (after $4 \mathrm{~d}$ ).

\section{Scanning electron microscopy}

Two types of SEM were used in this study. For measurements of pit membrane pores, freeze-dried specimens were split in a tangential plane, coated with platinum for $4 \mathrm{~min}$ at $10 \mathrm{~mA}$ in a sputter coater (Emitech, Ashford, UK), and observed with a field emission SEM at a voltage of $2 \mathrm{kV}$ (Zeiss UltraPlus FESEM; Thornwood, NY, USA).

The longest axis of 100 visible pit membrane pores $\left(D_{\mathrm{p}}\right)$ from several vessels was measured using ImageJ software (Rasband, 1997-2004). The relationship between the airseeding pressure $\left(P_{\mathrm{a}}\right)$ at a given pit membrane pore diameter $\left(D_{\mathrm{p}}\right)$ was calculated as follows: $P_{\mathrm{a}}=4 \gamma \cos \theta D_{\mathrm{p}}^{-1}$, where $\gamma$ is the surface tension of water $\left(0.073 \mathrm{~N} \mathrm{~m}^{-1}\right.$ at $\left.20^{\circ} \mathrm{C}\right)$, and $\theta$ is the contact angle of the air-water-membrane interface (assumed to be zero because of hydrophilic membrane components).

A conventional SEM (JEOL JSM-6360, Tokyo, Japan) at a voltage of $10 \mathrm{kV}$ was used to measure additional intervessel pit and vessel parameters. Dried, untreated wood specimens were split in a tangential plane, fixed to aluminum stubs with an electron-conductive carbon sticker, and coated with gold using a sputter coater (SPI Supplies, West Chester, PA, USA) for 2 min. Horizontal pit membrane diameter $\left(D_{\mathrm{m}}\right)$, pit aperture shape $\left(A P_{\mathrm{f}}\right.$, short/long axis of pit aperture), and aperture fraction $\left(F_{\text {ap }}=\right.$ aperture area per pit membrane area) were measured on 50 pits per species from several vessels. The thickness of vessel wall thickenings $\left(L_{\mathrm{t}}\right)$, and their number per axial vessel length $\left(T L^{-1}\right)$ was also measured. 
New

Phytologist

\section{Transmission electron microscopy}

Frozen samples were cut into $2 \mathrm{~mm}^{3}$ blocks and fixed overnight in Karnovsky's fixative at room temperature (Karnovsky, 1965). After washing in $0.2 \mathrm{M}$ phosphate buffer at $\mathrm{pH} 7.3$, the specimens were postfixed in $2 \%$ buffered osmium tetroxide for $1-2 \mathrm{~h}$ at room temperature, washed again, and dehydrated through a graded propanol series (30, 50, 70, 90\%). Afterwards, specimens were stained with $118 \mathrm{mM}$ uranyl acetate dissolved in ethanol for at least $30 \mathrm{~min}$ at $37^{\circ} \mathrm{C}$, and rinsed three times with propanol $100 \%$. The propanol was replaced by propylenoxide, which was gradually replaced with epon resin (SigmaAldrich) using a $2: 1$ solution for $15 \mathrm{~min}, 1: 1$ for $30 \mathrm{~min}, 1: 2$ for $1 \mathrm{~h}$, and overnight in 100\% epon at room temperature. The epon resin was then replaced once again and polymerized at $60^{\circ} \mathrm{C}$ for $48 \mathrm{~h}$. Embedded samples were trimmed with a razor blade and sectioned with an ultramicrotome (Ultracut, Reichert-Jung, Vienna, Austria). Transverse sections $1-2 \mu \mathrm{m}$ thick were cut with a glass knife, heat-fixed to glass slides, stained with $0.5 \%$ toluidine blue $\mathrm{O}$ in $0.1 \mathrm{M}$ phosphate buffer, and mounted in DPX (Agar Scientific). Resin-embedded material was prepared for TEM by cutting transverse, ultrathin sections between 60 and $90 \mathrm{~nm}$ using a diamond knife. The sections were attached to 300 mesh hexagonal copper grids (Agar Scientific) and stained manually with lead citrate for $1 \mathrm{~min}$. Observations were carried out using a Philips 400 TEM (Philips, Eindhoven, the Netherlands) at $80 \mathrm{kV}$ accelerating voltage and digital images were taken using a TVIPS camera (Tietz Video and Image Processing Systems GmbH, Gauting, Germany). Image analysis was undertaken using ImageJ software on at least 25 measurements to define the thickness of the intervessel pit membranes $\left(T_{\mathrm{m}}\right)$. The pit chamber depth $\left(L_{\mathrm{p}}\right)$ was measured as the distance from the inner side of the aperture to the surface of a nonaspirated, flat pit membrane on at least 15 pits (Fig. 3).

\section{Evaluating relationships}

Correlation statistics between variables were conducted using SPSS (SPSS Inc., http://www.spss.com), using linear ordinary least-squares regression. Although not all trait correlations need be linear, our ability to meaningfully distinguish nonlinear correlations from linear ones was weak given our limited sample size of $n=7$ taxa.

\section{Results}

\section{Vulnerability curves}

The species studied showed a wide range of cavitation resistance (Fig. 1). The two most vulnerable species (MCP (mean $\pm \mathrm{SE}):$ A. saccharinum, $-1.26 \pm 0.08 \mathrm{Mpa}$; A. negundo,

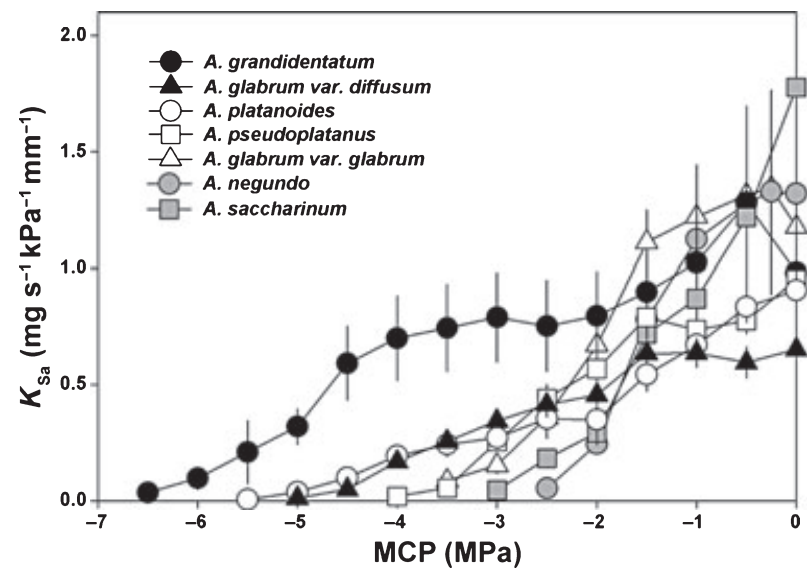

Fig. 1 Vulnerability curves of seven Acer species, showing the cumulative drop in stem-specific conductivity using the standard centrifuge method (A. glabrum var. diffusum, A. platanoides, A. pseudoplatanus and $A$. saccharinum) or the comparable spinning method (three remaining species taken from Christman et al., 2009; mean $\pm \mathrm{SE}, n=6$ stems). $\mathrm{MCP}$, mean cavitation pressure; $K_{\mathrm{Sa}}$ hydraulic conductivity per stem cross-sectional area.

$-1.68 \pm 0.08 \mathrm{MPa}$ ) had the highest initial $K_{\mathrm{Sa}}$ and showed the steepest decline to nearly zero at a xylem pressure of -2.5 to $-3.0 \mathrm{MPa}$. The three species with an intermediate resistance to cavitation (MCP: A. glabrum var. glabrum, $-2.25 \pm 0.14 \mathrm{Mpa} ; A$. platanoides, $-2.29 \pm 0.21 \mathrm{MPa}$; A. pseudoplatanus, $-2.29 \pm 0.14 \mathrm{MPa}$ ) also had intermediate initial $K_{\mathrm{Sa}}$, and reached zero conductivity between -4 and $-5.5 \mathrm{MPa}$. The two most resistant species, $A$. grandidentatum $(\mathrm{MCP}=-3.33 \pm 0.55 \mathrm{MPa})$ and $A$. glabrum var. diffusum (MCP $=-3.06 \pm 0.19 \mathrm{MPa})$, had intermediate to low values of $K_{\mathrm{Sa}}$ and reached near-zero conductivity at -6.5 and $-5 \mathrm{MPa}$, respectively. MCP averaged $c .8 \%$ more negative than $\mathrm{P} 50$, and the two measures were highly correlated $\left(r^{2}=0.96\right.$; Tables 2,4$)$.

\section{Correlations between xylem anatomy and MCP}

Many pit features were strongy correlated with MCP. More cavitation-resistant Acer species had shallower pit chambers $\left(L_{\mathrm{p}}, P<0.001\right)$ including thicker pit membranes $\left(T_{\mathrm{m}}\right.$, $P=0.001)$ with, on average, smaller pores $\left(D_{\mathrm{p}}, P=0.005\right)$ than more vulnerable species (Figs 2, 3; Table 2). The mean $D_{\mathrm{p}}$ value was, on average, $5.9 \pm 1.00$ times smaller than the pore size predicted to air-seed at the species' MCP, reflecting the fact that it is the largest pore rather than the average that is responsible for air-seeding. Less strong correlations (but still significant at $P=0.05$ ) were found between MCP and pit aperture shape $\left(A P_{\mathrm{f}}, P=0.024\right)$ and aperture fraction $\left(F_{\text {ap }}, P=0.033\right)$ : more cavitation-resistant species had narrower elliptical apertures, which were also smaller in area compared with the entire pit membrane surface than their more vulnerable relatives (Fig. 2). 


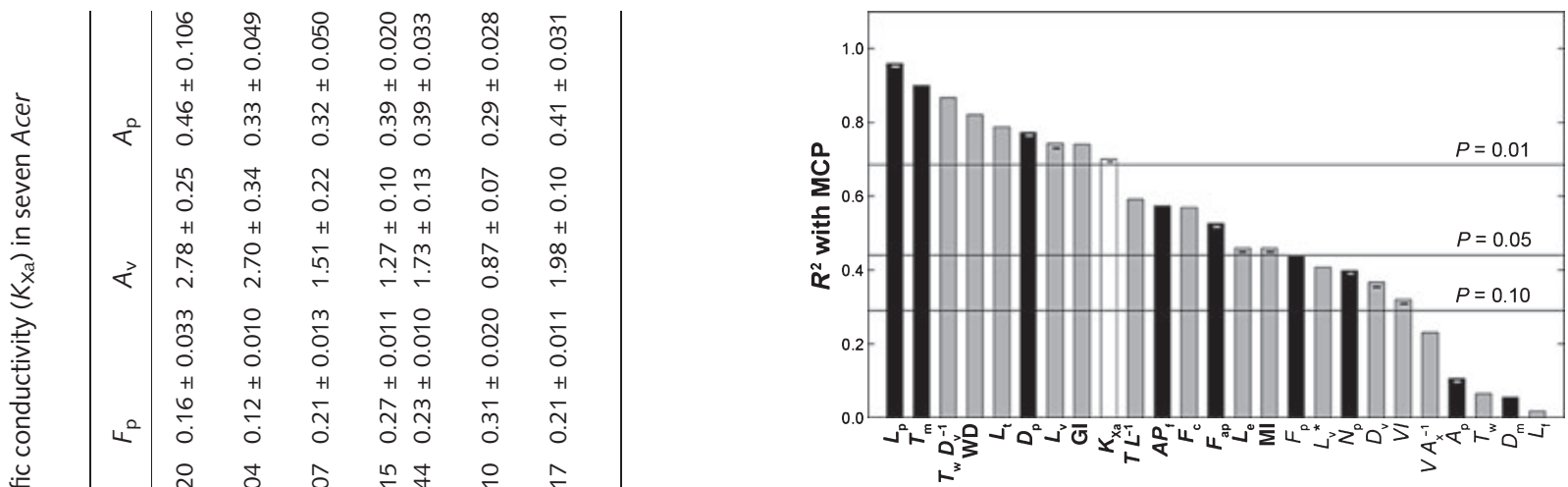

Fig. $2 R^{2}$ values of selected wood anatomical traits (abbreviated according to Table 1) with mean cavitation pressure (MCP). Negative signs indicate a negative relationship, meaning that an increase in a particular trait makes stems more vulnerable to cavitation (less negative MCP). Black bars, pit-level traits; gray bars, tissue-level traits; white bar, xylem-specific conductivity $\left(K_{x_{a}}\right)$.

There was a marginally significant tendency for MCP to become less negative as pit number increased $\left(N_{\mathrm{p}}\right.$, $P=0.064)$, but there was no relationship for pit area per vessel $\left(A_{\mathrm{p}}\right)$. More negative MCP was also associated with an increase in the fraction of vessel wall area occupied by pits $\left(F_{\mathrm{p}}, P=0.054\right)$. The diameter of the pit membrane was not important (Fig. 2, $D_{\mathrm{m}}$ ).

Mean cavitation pressure was positively correlated with wood strength parameters, such as thickness-to-span ratio of vessels $\left(T_{\mathrm{w}} D_{\mathrm{v}}^{-1}, P=0.001\right)$ and WD $(P=0.002$ Fig. 2). Intervessel wall thickness $\left(T_{\mathrm{w}}\right)$ and fibre length $\left(L_{\mathrm{f}}\right)$, however, showed no correlation.

Vessel size variables showed a complex relationship to MCP. Vessel diameter $D_{\mathrm{v}}$ was not well related to MCP (Fig. 2; $P=0.075$ ), but the untransformed mean vessel length $L_{\mathrm{v}}$ was: longer vessels tended to be more vulnerable than shorter ones by this measure $(P=0.006$; Fig. 2$)$. Longer vessel elements were also associated with greater vulnerability, though less strongly $\left(L_{\mathrm{e}}, P=0.045\right.$; Fig. 2$)$. Log-transformed mean vessel length $L_{\mathrm{v}}{ }^{*}$, however, was only marginally correlated with MCP $(P=0.062$; Fig. 2$)$. The unimportance of $D_{\mathrm{v}}$ resulted in no correlation between VI and MCP (Fig. 2; VI), but the MI $\left(\mathrm{VI} \times L_{\mathrm{e}}\right)$ was weakly correlated $(P=0.048$; Fig. 2$)$, probably because of the significant $L_{\mathrm{e}}$ relationship.

Surprisingly, there was a strong positive relationship between MCP and vessel GI $(P=0.006$; Figs 2,4$)$, such that a higher GI was associated with greater cavitation resistance. Similarly, greater vessel contact fraction was also linked to more negative $\mathrm{MCP}\left(F_{\mathrm{c}}, P=0.025\right.$; Fig. 2$)$. Another unexpectedly strong correlation was found between MCP and the thickness of the sculpturing on the inner vessel walls $L_{\mathrm{t}}(P=0.004$; Figs 2,5$)$, and there was an additional relationship with the density of these thickenings per axial vessel length, $T L^{-1}(P=0.022$; Figs 2, 5; Table 3$)$. 
New

Phytologist

Fig. 3 Tangential longitudinal scanning electron microscopy surfaces (a, c, e) and transverse transmission electron microscopy sections $(b, d, f)$ illustrating differences in pit structure in the most cavitation-susceptible Acer saccharinum $(a, b)$, the intermediate Acer platanoides $(c, d)$, and in the most cavitation-resistant Acer grandidentatum (e, f). The more cavitation-resistant Acer species had, on average, thicker pit membranes $\left(T_{\mathrm{m}}\right.$; b vs $f$ ) with fewer and smaller pores ( $D_{\mathrm{p}}$; a vs e) and a shallower pit chamber ( $L_{p} ; b$ vs f). The elliptical shape visible in the central part of the pit membrane $(a, e)$ corresponds to the underlying elliptical pit aperture.
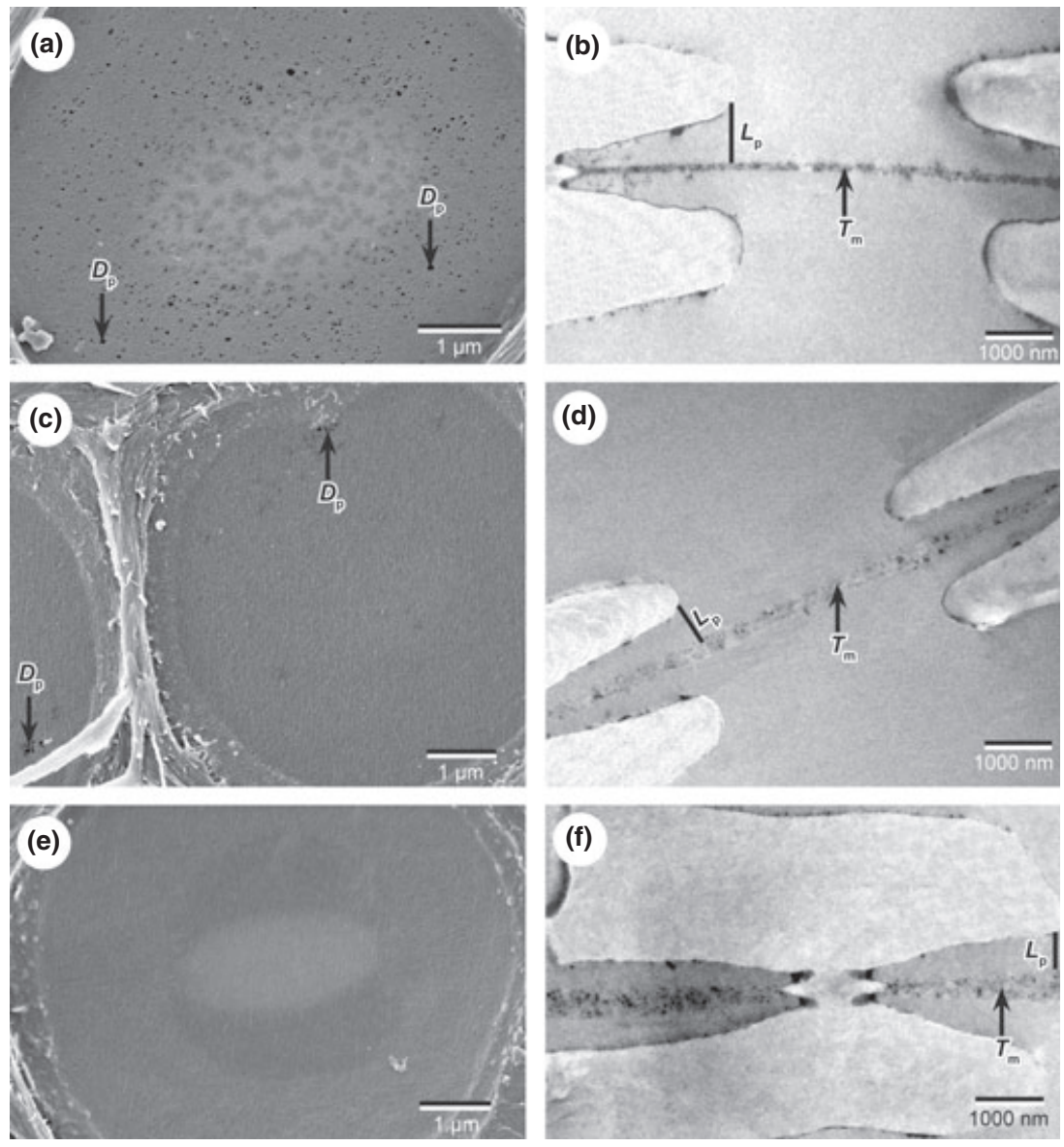

We found a strong relationship between greater cavitation resistance and lower xylem-specific conductivity $\left(K_{\mathrm{Xa}}\right.$, $P=0.009$; Fig. 2). This trade-off is also reflected in the stem-specific conductivities shown in Fig. 1: more cavitation-resistant species tended to have a lower initial $K_{\mathrm{Sa}}$ than the more vulnerable species.

\section{Correlations between xylem anatomical characters and xylem-specific conductivity $\left(K_{\mathrm{Xa}}\right)$}

There was evidence for the intuitive positive link between vessel size and $K_{\mathrm{Xa}}$ (Fig. 6) with both measures of vessel length $\left(L_{\mathrm{v}}, P=0.001 ; L_{\mathrm{v}}{ }^{*}, P=0.009\right)$ and $D_{\mathrm{v}}(P=0.019$; Fig. 6) showing strong positive relationships with $K_{\mathrm{Xa}} . L_{\mathrm{e}}$ was also positively related to $K_{\mathrm{Xa}}(P=0.012)$. Vessel density $V A_{\mathrm{x}}^{-1}$ was not correlated with $K_{\mathrm{Xa}}$, but VI showed a correlation $(P=0.015)$ as a result of the positive $D_{\mathrm{v}}$ relationship. The $L_{\mathrm{e}}$ correlation resulted in a strong relationship between $K_{\mathrm{X}}$ and MI $(P=0.002)$. Interestingly, higher GI and $F_{\mathrm{c}}$ were strongly coupled to lower $K_{\mathrm{X} a}\left(\mathrm{GI}, P=0.005 ; F_{\mathrm{c}}, P=0.004\right)$.

Several pit characters were strongly correlated with increasing $K_{\mathrm{X}}$ (Fig. 6), such as higher aperture fractions $\left(F_{\text {ap }}, P=0.003\right)$, deeper pit chambers $\left(L_{\mathrm{p}}, P=0.011\right)$, and thinner intervessel pit membranes $\left(T_{\mathrm{m}}, P=0.011\right)$. A decrease in the fraction of vessel walls occupied by pits was associated with higher $K_{\mathrm{Xa}}\left(F_{\mathrm{p}}, \quad P=0.015\right)$, probably because lower pit fractions were associated with longer and wider vessels (Table 4). There was a marginally significant trend for $K_{\mathrm{Xa}}$ to increase with greater $N_{\mathrm{p}}(P=0.06)$. No other measured pit parameter was found to be important $\left(D_{\mathrm{m}}, D_{\mathrm{p}}, A_{\mathrm{p}}, A P_{\mathrm{f}}\right.$, Fig. 6).

Wood density and thickness-to-span ratio $\left(T_{\mathrm{w}} D_{\mathrm{v}}^{-1}\right)$ were both negatively associated with $K_{\mathrm{X}}$ (WD, $P=0.009$; $T_{\mathrm{w}} D_{\mathrm{v}}^{-1}, P=0.034$; Fig. 6). Vessel wall sculpturing parameters $\left(L_{\mathrm{t}}, T L^{-1}\right)$ and fiber length $\left(L_{\mathrm{f}}\right)$ were unimportant (Fig. 6).

\section{Traits important for the safety vs efficiency trade-off}

A few key traits showed strong relationships with both MCP and $K_{\mathrm{Xa}}$ (Fig. 7), and hence are potentially involved in a cause-and-effect explanation for the observed safetyefficiency trade-off. Traits that were associated with enhanced cavitation resistance and lower conductivity (Fig. 7, lower right box, $P \leq 0.05$ ) were $T_{\mathrm{w}} D_{\mathrm{v}}^{-1}$, WD, GI, $F_{\mathrm{c}}, T_{\mathrm{m}}$ and $F_{\mathrm{p}}$. Traits associated with high conductivity but low cavitation resistance (Fig. 7 , upper left box, $P \leq 0.05$ ) were $L_{\mathrm{v}}, L_{\mathrm{e}}, L_{\mathrm{p}}, F_{\mathrm{ap}}$, and MI. 

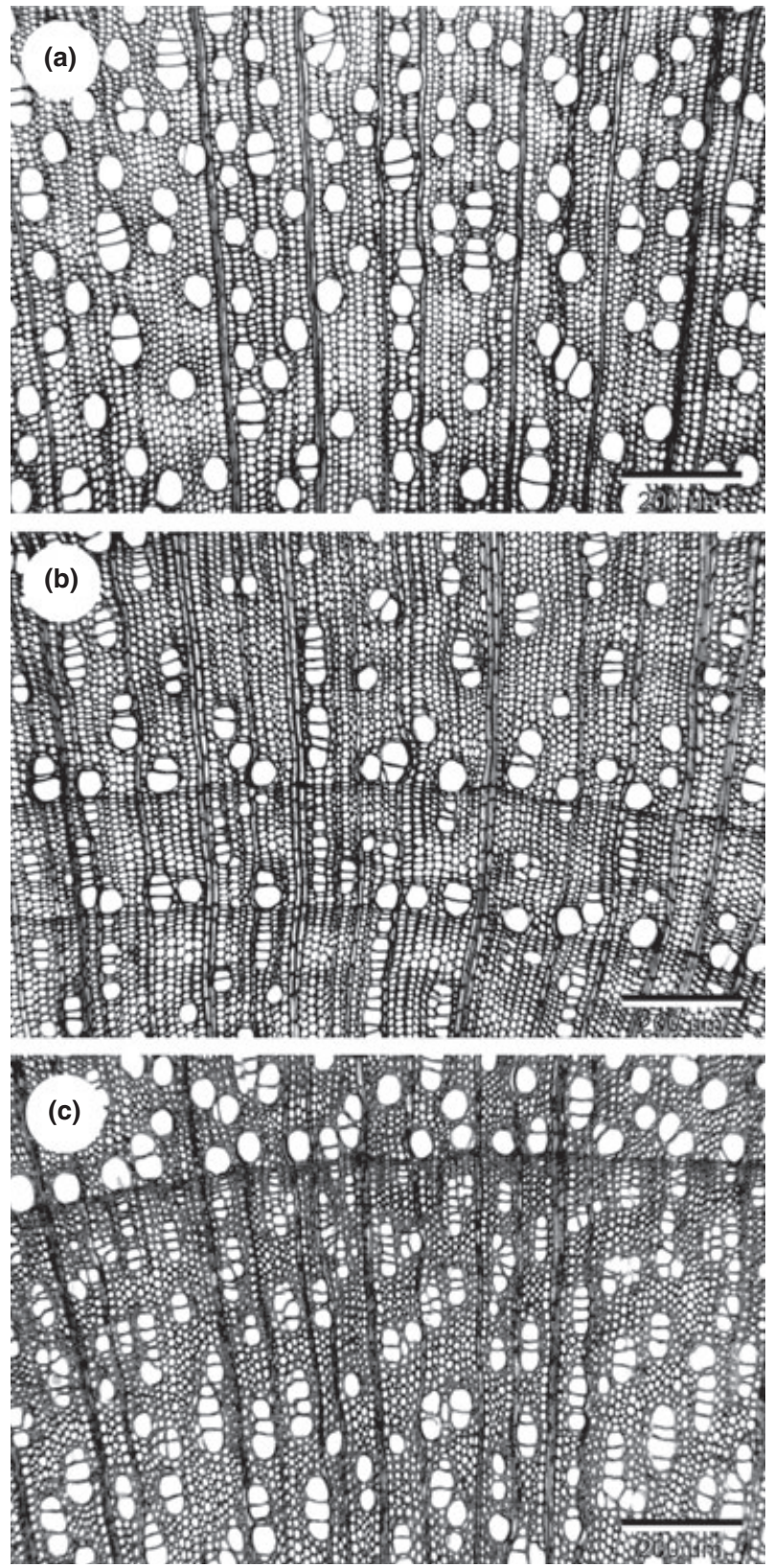

Fig. 4 Pictures of transverse light microscope sections showing variation in vessel grouping patterns in the most cavitationsusceptible species, Acer saccharinum (a), the intermediate Acer pseudoplatanus (b), and in the most cavitation-resistant Acer grandidentatum (c). The more cavitation-resistant Acer species had, on average, more and larger vessel multiples, resulting in a higher vessel grouping index and contact fraction.

\section{Discussion}

Superficially, the wood anatomy of the seven Acer taxa studied lacked obvious variation using standard light microscope observations (Fig. 4), despite a $2 \mathrm{MPa}$ range in MCP and a clear difference in stem-specific hydraulic conductivity (Fig. 1). However, a more detailed examination using LM,
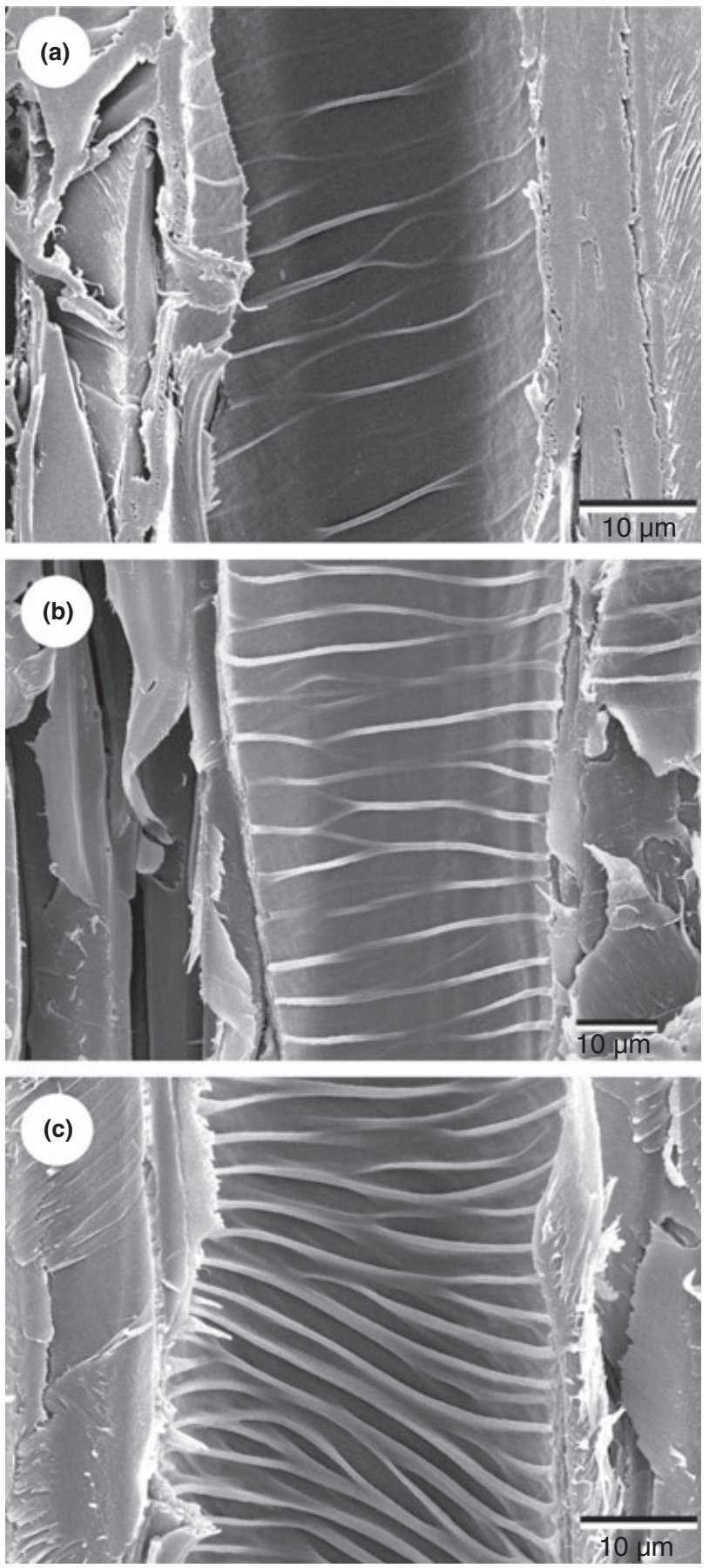

Fig. 5 Scanning electron microscope pictures of tangential longitudinal surfaces showing variation in vessel wall thickenings on the inner walls in the most cavitation susceptible Acer saccharinum (a), the intermediate A. glabrum var. glabrum (b), and in the most cavitation resistant $A$. grandidentatum (c). Within Acer, the more cavitation resistant species had thicker and denser sculpturing patterns on their inner vessel walls.

SEM and TEM revealed a wide range of less obvious anatomical characteristics that showed a strong relationship with MCP (Figs 2-5) and xylem-specific conductivity (Fig. 6). Some of these correlations are empirically demon- 


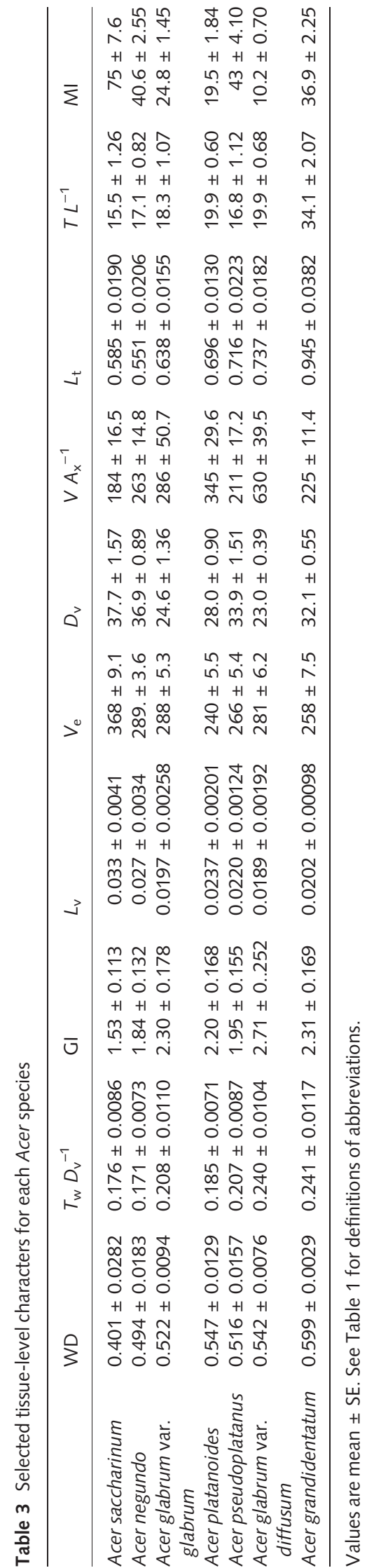

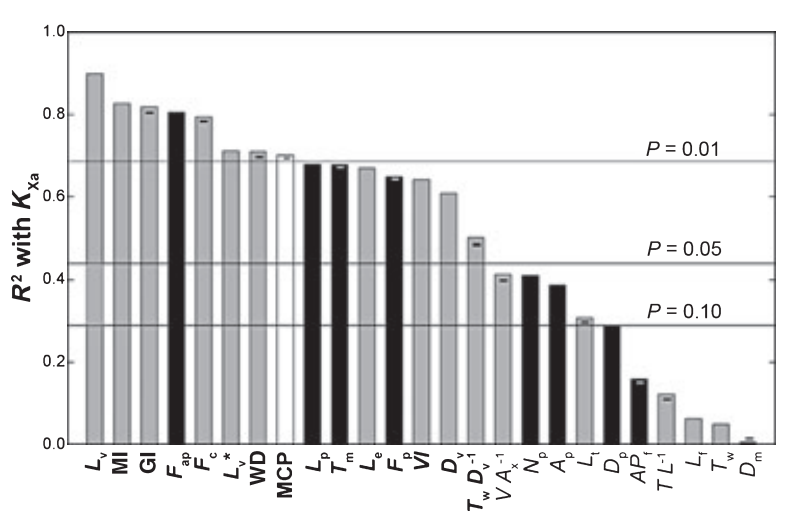

Fig. $6 R^{2}$ of selected wood anatomical traits (abbreviated according to Table 1$)$ with xylem conductivity per xylem area $\left(K_{x_{a}}\right)$. Negative signs indicate a negative relationship, meaning that an increase in a particular feature decreases $K_{\mathrm{xa}}$ in stems. Black bars, pit-level traits; gray bars, tissue-level traits; white bar, mean cavitation pressure (MCP).

strated for the first time in this study, and all are discussed below in relation to hypothetical mechanisms of cavitation and hydraulic conductance. The trends we found in Acer are not always similar to patterns reported from other clades, suggesting multiple evolutionary pathways for achieving cavitation resistance and hydraulic conductivity.

\section{Pit structure was more strongly linked to MCP than pit quantity}

Our results suggest that Acer species have evolved different MCPs primarily by altering pit structure, and secondarily by altering $N_{\mathrm{p}}$, although additional factors such as the role of calcium may also influence cavitation resistance (Herbette \& Cochard, 2010). The pit membrane structures that corresponded with more negative MCP make sense in light of the air-seeding mechanism (greater $T_{\mathrm{m}}$, lower $D_{\mathrm{p}}$; Fig. 2). Developmental mistakes causing a weak spot or a large pore in pit membranes are hypothetically less severe in species with higher $T_{\mathrm{m}}$ and lower $D_{\mathrm{p}}$, which would decrease the likelihood of cavitation by air-seeding (Choat et al., 2008; Christman et al., 2009; Jansen et al., 2009). The extreme pore diameter predicted from the MCP averaged six times wider than the average $D_{\mathrm{p}}$ across all species, suggesting that shifts in the extreme pore size (and hence $\mathrm{MCP}$ ) were achieved by proportional shifts in the average pore size.

Greater cavitation resistance was also associated with features that would minimize mechanical stresses on the aspirated pit membrane (Fig. 2; smaller $L_{\mathrm{p}}$, larger $A P_{\mathrm{f}}$, and smaller $\left.F_{\mathrm{ap}}\right)$. Shallower pit chambers (smaller $L_{\mathrm{p}}$ ) reduce membrane stretching before aspiration against the pit border. Once aspirated, further stress would be minimized by narrower slit-like apertures (greater $A P_{\mathrm{f}}$ ) that occupy a proportionally smaller area of the pit border (smaller $F_{\text {ap }}$ ). All 


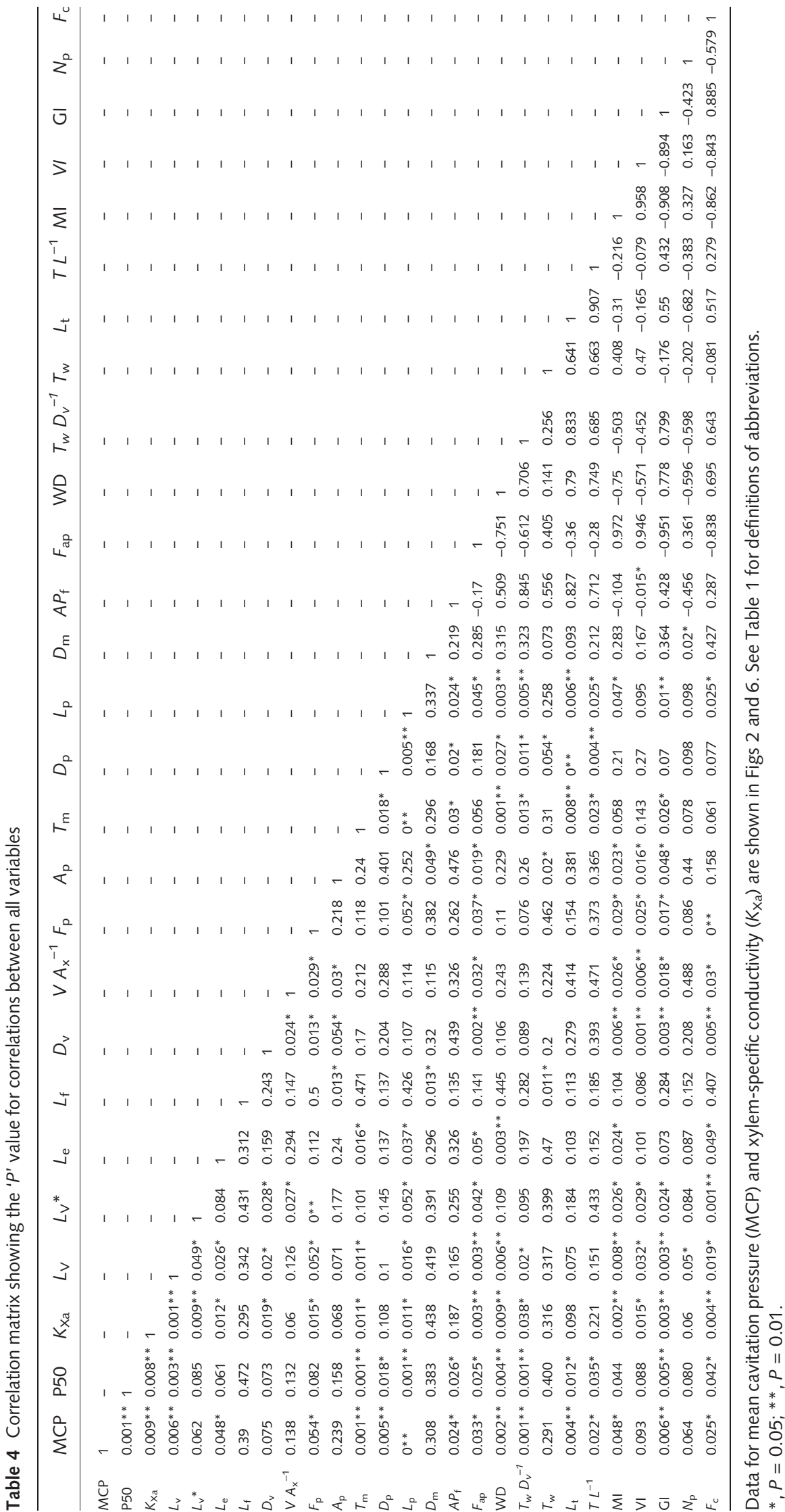




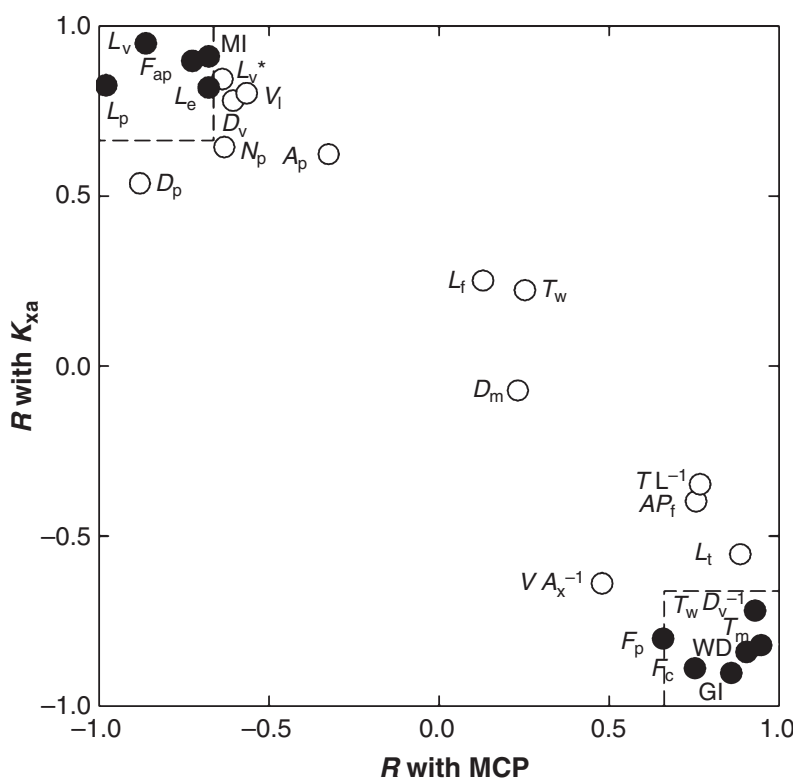

Fig. 7 Correlation coefficient $(R)$ values of wood anatomical features with specific conductivity $\left(K_{X_{a}}\right)$ vs mean cavitation pressure (MCP). Traits within the dashed boxes are significantly correlated with $K_{\mathrm{Xa}}$ and MCP $(P \leq 0.05)$, and are possible candidates for explaining the cause-and-effect basis of the safety-efficiency tradeoff. Traits are abbreviated according to Table 1.

these features, together with greater membrane thickness, would minimize expansion of pores beyond the critical radius for air-seeding (Choat et al., 2004) and inhibit membrane rupture. The hydraulic importance of proportionally smaller apertures (Domec et al., 2006; Pittermann et al., 2010) and reduced chamber depth (Hacke \& Jansen, 2009) has also been identified in conifer species with torus-margo membranes.

The marginally significant tendency for smaller $N_{\mathrm{p}}$ to associate with greater cavitation resistance suggests that the probability of developing a rare leaky pit is more a function of pit number per vessel than total pit area $\left(A_{\mathrm{p}}\right)$. Although the vessel surface area $A_{\mathrm{v}}$ tended to decline with lower MCP (primarily because of shorter vessels; Fig. 2), $A_{\mathrm{p}}$ did not decline because of a concurrent increase in $F_{\mathrm{p}}$ (Fig. 2). Our data suggests that reanalyzing previous $A_{\mathrm{p}}$ data sets (Wheeler et al., 2005; Hacke et al., 2006) in terms of $N_{\mathrm{p}}$ would result in even stronger relationships with MCP.

\section{Wood (WD) and vessel strength $\left(T_{\mathrm{w}} D_{\mathrm{v}}{ }^{-1}\right)$ parameters strongly scale with MCP}

Our study confirms many previous ones in showing strong positive correlations between MCP and WD and thicknessto-span ratio of vessels, $T_{\mathrm{w}} D_{\mathrm{v}}^{-1}$ (Hacke et al., 2001; Jacobsen et al., 2005, 2007; Sperry et al., 2006; Chave et al., 2009; Onoda et al., 2009). Greater thickness-to-span ratio is interpreted as strengthening the vessel walls against implosion, which is rarely observed in wood because it is preceded by cavitation. WD is influenced more by the thickness-to-span of fibers than vessels, but a denser fiber matrix would also help support vessels. The correlation between $T_{\mathrm{w}} D_{\mathrm{v}}^{-1}$ and WD (Table 4) suggests that vessel and fiber contributions to strength were coordinated in Acer. This may not always be the case, and varying contributions of fiber and vessel traits to vessel implosion resistance may explain studies where correlations of WD or $T_{\mathrm{w}} D_{\mathrm{v}}^{-1}$ with cavitation resistance are weak (Cochard et al., 2008).

There are at least two interpretations of the cause and effect underlying a vessel strength-vulnerability relationship. The original interpretation (Hacke et al., 2001) was that cavitation-resistant plants tend to have more negative sap pressures, and hence need stronger walls. Wall strength and air-seeding pressure, however, could be determined by structurally independent features and so would not necessarily be causally linked. Alternatively, wall strength could directly determine the air-seeding pressure. As the wall distorts from higher negative pressures, air-seeding sites could arise because of the increasing mechanical stress. These sites could arise within the pit membranes via aspirated or stretching pit membranes, or possibly in other parts of the vessel wall through microfractures (Jacobsen et al., 2005). Which of the two interpretations is correct depends on the extent to which intervessel wall strength and vessel airseeding pressures can evolve independently.

\section{More cavitation-resistant Acer species have more and} longer radial vessel multiples and shorter vessels

Little effort has been paid to find a functional explanation for the variation in intervessel grouping across angiosperms (Carlquist, 1984, 2009; Rosell et al., 2007; Jansen et al., 2010). Recent theoretical insights into the connectivity of the three-dimensional vessel network found that increasing vessel connectivity (average number of vessels contacting a vessel) decreases resistance to cavitation by increasing the probability for the spread of embolism, while conductivity was increased by greater connectivity (Loepfe et al., 2007). These theoretical results contradict the vessel grouping hypothesis of Carlquist (1984), who states that xericadapted species with a ground tissue xylem similar to Acer (nonconductive fibres, no vasicentric tracheids) have more and larger vessel groups (higher connectivity) than their relatives growing in more mesic environments. In theory, the larger vessel groups would be needed to bypass the more frequent embolisms in arid habitats (Carlquist, 2009).

Our data provide the first empirical test of the importance of vessel grouping, and support Carlquist's hypothesis rather than the Loepfe et al. (2007) model. Greater GI and vessel contact fraction, $F_{\mathrm{c}}$, were strongly correlated with more negative MCP (Fig. 2) and lower $K_{\mathrm{Xa}}$ (Fig. 6). The 
same was true for the portion of wall devoted to intervessel pitting, $F_{\mathrm{p}}$.

The relationships between GI vs MCP and $K_{\mathrm{Xa}}$ could result from the importance of vessel length for determining these traits. Shorter vessels $\left(L_{\mathrm{v}}\right.$ and $\left.L_{\mathrm{v}}{ }^{*}\right)$ were highly correlated with greater GI (Table 4), probably because there is less axial distance to make the necessary connections with other vessels, resulting in more and greater multiples. Vessel length was also the only vessel size parameter that was correlated with MCP: the shorter the $L_{\mathrm{v}}$, the more negative the MCP (Fig. 2). Finally, vessel length was the most important size parameter for explaining variation in $K_{\mathrm{Xa}}\left(L_{\mathrm{v}}, L_{\mathrm{v}}{ }^{*}\right.$, Fig. 6).

\section{The importance of vessel length $\left(L_{v}, L_{v}{ }^{*}\right)$ vs vessel diameter $\left(D_{\mathrm{v}}\right)$ in Acer}

Vessel length in Acer may be causally related to both cavitation resistance and conductivity, and hence responsible for the vessel grouping result as well as the observed safety vs efficiency trade-off (Fig. 7). Shorter vessels had fewer pits (Table 4), and fewer pits per vessel (lower $N_{\mathrm{p}}$ ) were marginally linked to greater cavitation resistance (Fig. 2), possibly because of the 'rare pit' mechanism. Even though shorter vessels were also narrower (Table 4), vessel diameter was not correlated with MCP or $N_{\mathrm{p}}$ (Fig. 2). The seeming unimportance of vessel diameter for cavitation resistance in Acer contradicts observations from other woody angiosperm comparisons where species with wider vessels tend to be more vulnerable (Carlquist, 1977; Ellmore \& Ewers, 1985; Hargrave et al., 1994; Wheeler et al., 2005; Hacke et al., 2006; Cai \& Tyree, 2010). Apparently, $D_{\mathrm{v}}$ in Acer is uncoupled from the observed pit and connectivity features that hypothetically influence vulnerability to cavitation.

Shorter vessel length was also strongly related to lower $K_{\mathrm{Xa}}\left(L_{\mathrm{v}}, L_{\mathrm{v}}^{*}\right.$, Fig. 2), more so than narrower $D_{\mathrm{v}}$ (Fig. 2). The importance of longer vessels, presumably, is that they reduce how often water must flow through high resistance end walls. Assuming that the Hagen-Poiseuille flow resistance estimates vessel lumen resistance, and that measured resistance equals lumen plus end-wall resistance, the end walls in our species accounted for $73 \pm 0.05 \%$ of the xylem flow resistance. This high proportion is consistent with the greater role for $L_{\mathrm{v}}$ and pit features $\left(F_{\mathrm{ap}}, L_{\mathrm{p}}, T_{\mathrm{m}}\right)$ in explaining variation in $K_{\mathrm{Xa}}$ than $D_{\mathrm{v}}$ (Fig. 6).

Our data generally suggest that the untransformed vessel length, $L_{\mathrm{v}}$, is more strongly correlated with functional parameters than the log-transformed mean, $L_{\mathrm{v}}{ }^{*}$ (Figs 2, 6; Table 4). The untransformed mean is biased towards the longer vessels in the short-skewed vessel length distribution. Its greater statistical significance suggests that the few very long vessels may play a disproportional role in determining $\mathrm{MCP}$ and $K_{\mathrm{Xa}}$.

\section{$L_{\mathrm{e}}$ relationships: convergence or causation?}

Some authors have argued that shorter vessel elements are mechanically better adapted to cope with increasing xylem pressures (Carlquist, 1975), or they provide more opportunity to trap local air bubbles as a result of a higher frequency of overlapping vessel member ends (Carlquist, 1982). Others are skeptical about a possible function of $L_{\mathrm{e}}$ (Baas et al., 1983), or consider it to be functionally meaningless (Zimmermann, 1983). Our data demonstrate that $L_{\mathrm{v}}$ is more strongly linked with MCP and $K_{\mathrm{Xa}}$ than $L_{\mathrm{e}}$, suggesting that vessel length is hydraulically more meaningful than vessel element length (Figs 2, 6). The correlations we observed for $L_{\mathrm{e}}$ may result from the link between $L_{\mathrm{e}}$ and $L_{\mathrm{v}}$ (Table 4). The link between $L_{\mathrm{e}}$ and $L_{\mathrm{v}}$ could result from how vessel length is determined developmentally (Nijsse, 2004). Accordingly, $L_{\mathrm{e}}$ may be important only to the extent it influences the more functionally relevant $L_{\mathrm{v}}$. However, the possibility remains that there could be a developmental coupling between $L_{\mathrm{e}}$ and important intervessel pit qualities.

\section{The extent of vessel wall thickenings in Acer is correlated with MCP}

This new finding (Figs 2, 5) supports the idea that the presence of vessel wall thickenings can be linked with drought adaptation (Carlquist, 1966, 1975), although vessel wall sculpturing is also common in the less xeric Mediterranean and the far more mesic cool temperate flora that experience frost (Carlquist, 1966; Baas et al., 1983; Baas \& Schweingruber, 1987).

There are no conclusive data, however, on the functional role of vessel wall thickening. A simple explanation is that the thickenings acts to strengthen the vessel wall in more arid-adapted taxa, which experience more negative xylem pressures. In addition, it could minimize flow resistance by reducing shear forces at the vessel wall (Jeje \& Zimmermann, 1979). Vessel wall thickening may also decrease the contact angle between water and conduit walls to nearly zero, causing enhanced wettability of the walls that may reduce embolism formation and facilitate refilling (Kohonen \& Helland, 2009). Our SEM observations convincingly show that the wall thickening only occurs in zones without intervessel pits (Fig. 5). Further research is required to verify whether this asymmetrical sculpturing pattern in Acer can be related to the possible functions put forward in the literature for intact helical thickenings.

\section{Predictive value of ecological wood anatomy indices (VI, MI)}

The structural basis of cavitation and conductivity is probably too complex to be captured by simplified indices that lack crucial hydraulic parameters such as pith structure and 
$L_{\mathrm{v}}$. Consequently, VI was not useful for predicting cavitation resistance in Acer (Fig. 2), because neither of its component variables $\left(D_{\mathrm{v}}\right.$ and $\left.V A_{\mathrm{x}}^{-1}\right)$ were related to MCP. However, VI was correlated with greater $K_{\mathrm{Xa}}$, primarily because of $D_{\mathrm{v}}$. MI fared much better than VI probably because of the importance of $L_{\mathrm{e}}$ : MI was weakly negatively linked to more vulnerable MCP (Fig. 2), and more strongly positively related to $K_{\mathrm{Xa}}$ (Fig. 6). These correlations support the value of MI as demonstrated in ecological wood studies across a broad range of angiosperms (Carlquist, 1977; Carlquist \& Hoekman, 1985; Patterson \& Tanowitz, 1989).

\section{Basis for the safety-efficiency trade-off}

The safety-efficiency trade-off we observed (Fig. 2) is in close agreement with the findings of an earlier study on six Acer species occurring in the French Alps (Tissier et al., 2004). Potential traits explaining this trade-off are identified in Fig. 7. As discussed earlier, $L_{\mathrm{v}}$ emerges as a trait that is arguably central to the safety-efficiency trade-off in Acer, being functionally linked to both MCP and $K_{\mathrm{Xa}}$. The involvement of GI, $F_{\mathrm{c}}, F_{\mathrm{p}}$ and $L_{\mathrm{e}}$ in the trade-off may simply follow from the importance of $L_{\mathrm{v}}$. The pit features $T_{\mathrm{m}}, L_{\mathrm{p}}$ and $F_{\text {ap }}$ are also plausibly responsible for the safetyefficiency trade-off: thicker membranes, shallower chambers, and proportionally smaller apertures should all confer greater resistance to cavitation, and they may also increase flow resistance through end walls.

The involvement of $T_{\mathrm{w}} D_{\mathrm{v}}^{-1}$ and WD in the trade-off is more ambiguous. While these features can be linked to MCP either causally or convergently, their link to $K_{\mathrm{Xa}}$ is less obvious. It does not seem to be through vessel diameter, because $D_{\mathrm{v}}$ is not correlated with either variable (Table 4). Instead, the link may be through intervessel pit structure: $T_{\mathrm{w}} D_{\mathrm{v}}^{-1}$ and WD were both strongly linked to $T_{\mathrm{m}}$ and $L_{\mathrm{p}}$, and were individually linked to $A P_{\mathrm{f}}$ and $F_{\mathrm{ap}}$ (Table 4). All these pit features arguably influence $K_{\mathrm{Xa}}$ as well as the mechanical strength of intervessel walls. Thus, intervessel wall structure may be the source of a trade-off between mechanical strength and hydraulic efficiency (cf. Carlquist, 1975).

\section{Conclusions}

Xylem hydraulic properties in Acer appear to be determined by a complex interaction between pit and tissue characters. The indices from the ecological wood anatomy tradition are simplified, but the MI, in particular, proves to be informative. In many cases, the web of trait correlations was consistent with proposed mechanisms for cavitation by airseeding, resistance to vessel implosion, and xylem hydraulic conductance. The safety-efficiency conflict in Acer may have resulted from the involvement of vessel length and in- tervessel pit structures in determining both MCP and $K_{\mathrm{Xa}}$ Vessel length may also explain the involvement of vessel grouping traits with $\mathrm{MCP}$ and $K_{\mathrm{Xa}}$. Some statistically important traits, such as vessel wall thickening and vessel element length, have a more ambiguous functional basis. More comparative and experimental work is necessary before xylem function can be mechanistically predicted from structure. It seems likely that MCP and $K_{\mathrm{Xa}}$ can be achieved by a variety of structural combinations, and the trade-offs and correlations that we observed within Acer are not necessarily the same in other woody genera of angiosperms or across larger groups.

\section{Acknowledgements}

This study is made possible by a visit of F.L. to the Sperry laboratory (Salt Lake City, UT, USA), granted by the Fund for Scientific Research-Flanders (Belgium). We thank the technicians of the Electron Microscopy Section of Ulm University (Germany), and the Center for Advanced Microscopy (ANU), and Miss Nathalie Geerts (K.U. Leuven, Belgium) for technical assistance. The guidance of the McClellan family is much appreciated during the expedition in Sawtooth Canyon (UT, USA). This work has been financially supported by research grants of the K.U. Leuven (OT/05/35) and the Fund for Scientific Research-Flanders (Belgium) (G.0268.04; KaN 1.5.035.10). J.S.S. acknowledges financial support from NSF-IBN-0743148. Funding to S.J. was provided by a grant from the Ministry of Science, Research, and the Arts (Baden-Wurttemberg, Germany). F.L. is a postdoctoral fellow of the Fund for Scientific Research-Flanders (Belgium) (F.W.O. - Vlaanderen).

\section{References}

Alder NN, Pockman WT, Sperry JS, Nuismer S. 1997. Use of centrifugal force in the study of xylem cavitation. Journal of Experimental Botany 48 665-674.

Baas P, Schweingruber FH. 1987. Ecological trends in the wood anatomy of trees, shrubs and climbers from Europe. International Association of Wood Anatomists Bulletin, New Series 8: 245-274.

Baas P, Werker E, Fahn A. 1983. Some ecological trends in vessel characters. International Association of Wood Anatomists Bulletin, New Series 4: 141-159.

Brodribb TJ, Cochard H. 2009. Hydraulic failure defines the recovery and point of death in water-stressed conifers. Plant Physiology 149: $575-584$.

Cai J, Tyree MT. 2010. The impact of vessel size in vulnerability curves: data and models for within-species variability in saplings of aspen, Populus tremuloides Michx. Plant, Cell \& Environment 33: 1059-1069.

Carlquist S. 1966. Wood anatomy of Compositae: a summary, with comments on factors controlling wood formation. Aliso 6: 25-44.

Carlquist S. 1975. Ecological strategies of xylem evolution. Berkely, CA, USA: University of California Press.

Carlquist S. 1977. Ecological factors in wood evolution: a floristic approach. American Journal of Botany 64: 887-896. 
Carlquist S. 1982. Wood anatomy of Illicium (Illiciaceae). Phylogenetic, ecological, and functional interpretations. American Journal of Botany 69: 1587-1598.

Carlquist S. 1984. Vessel grouping in dicotyledon wood: significance and relationship to imperforate tracheary elements. Aliso 10: 505-525.

Carlquist S. 2001. Comparative wood anatomy: systematic, ecological, and evolutionary aspects of dicotyledon wood. Berlin, Germany: Springer-Verlag.

Carlquist S. 2009. Non-random vessel distribution in woods: patterns, modes, diversity, correlations. Aliso 27: 39-58.

Carlquist S, DeBuhr L. 1977. Wood anatomy of Penaeaceae (Myrtales): comparative, phylogenetic, and ecological implications. Botanical Journal of the Linnean Society 75: 211-227.

Carlquist S, Hoekman DA. 1985. Ecological wood anatomy of the southern Californian flora. International Association of Wood Anatomists Bulletin, New Series 6: 319-347.

Chave J, Comes D, Jansen S, Lewis SL, Swenson NG, Zanne AE. 2009. Towards a worldwide wood economics spectrum. Ecology Letters 12: 351-366.

Chave J, Muller-Landau HC, Baker TR, Easdale TA, ter Steege H, Webb CO. 2006. Regional and phylogenetic variation of wood density across 2456 neotropical tree species. Ecological Applications 16: 2356-2367.

Choat B, Cobb A, Jansen S. 2008. Structure and function of bordered pits: new discoveries and impacts on whole plant hydraulic function. New Phytologist 177: 608-626.

Choat B, Jansen S, Zwieniecki MA, Smets E, Holbrook NM. 2004. Changes in pit membrane porosity due to deflection and stretching: the role of vestured pits. Journal of Experimental Botany 55: 1569-1575.

Christman MA, Sperry JS, Adler FR. 2009. Testing the 'rare pit' hypothesis for xylem cavitation resistance in three species of Acer. New Phytologist 182: 664-674.

Cochard H, Braigah ST, Kleinhentz M, Eshel A. 2008. Is xylem cavitation resistance a relevant criterion for screening drought resistance among Prunus species? Journal of Plant Physiology 165: 976-982.

Cochard H, Damour G, Bodet C, Tharwat I, Poirier M, Améglio T. 2005. Evaluation of a new centrifuge technique for rapid generation of xylem vulnerability curves. Physiologia Plantarum 124: 410-418.

Domec J-C, Lachenbruch B, Meinzer FC. 2006. Bordered pit structure and function determine spatial patterns of air-seeding tresholds in xylem of Douglas-fir (Pseudotsuga menziesii; Pinaceae) trees. American Journal of Botany 93: 1588-1600.

Ellmore GS, Ewers FW. 1985. Hydraulic conductivity in trunk xylem of elm, Ulmus americana. International Association of Wood Anatomists Bulletin, New Series 6: 303-307.

Franklin GL. 1945. Preparation of thin sections of synthetic resins and wood-resin composites, and a new maceration method for wood. Nature 155: 51.

Hacke UG, Jansen S. 2009. Embolism resistance of three boreal conifer species varies with pit structure. New Phytologist 182: 675-686.

Hacke UG, Sperry JS, Feild TS, Sano Y, Sikkema EH, Pittermann J. 2007. Water transport in vesseless angiosperms: conducting efficiency and cavitation safety. International Journal of Plant Sciences 168: 1113-1126.

Hacke UG, Sperry JS, Pockman WT, Davis SD, McCulloh KA. 2001. Trends in wood density and structure are linked to prevention of xylem implosion by negative pressure. Oecologia 126: 457-461.

Hacke UG, Sperry JS, Wheeler JK, Castro L. 2006. Scaling of angiosperm xylem structure with safety and efficiency. Tree Physiology 26: 689-701.

Hargrave KR, Kolb KJ, Ewers FW, Davis SD. 1994. Conduit diameter and drought-induced embolism in Salvia mellifera Greene (Labiatae). New Phytologist 126: 695-705.

Herbette S, Cochard H. 2010. Calcium is a major determinant of xylem vulnerability to cavitation. Plant Physiology 153: 1932-1939.

Jacobsen AL, Ewers FW, Pratt RB, Paddock WA III, Davis SD. 2005. Do xylem fibers affect vessel cavitation resistance? Plant Physiology 139: 546-556.
Jacobsen AL, Pratt RB, Ewers FW, Davis SD. 2007. Cavitation resistance among 26 chaparral species of southern California. Ecological Monographs 77: 99-115.

Jansen S, Choat B, Pletsers A. 2009. Morphological variation of intervessel pit membranes and implications to xylem function in angiosperms. American Journal of Botany 96: 409-419.

Jansen S, Gortan E, Lens F, Lo Gullo MA, Trifilò P, Scholz A, Salleo S, Stein A, Nardini A. 2010. Do quantitative vessel and pit characters account for ion-mediated changes in the hydraulic conductance of xylem across angiosperms? New Phytologist, doi: 10.1111/j.14698137.2010.03448.x.

Jeje AA, Zimmermann MH. 1979. Resistance to water flow in xylem vessels. Journal of Experimental Botany 30: 817-827.

Karnovsky MJ. 1965. A formaldehyde-glutaraldehyde fixative of high osmolality for use in electron microscopy. Journal of Cell Biology 27: 137-138.

Kohonen MM, Helland A. 2009. On the function of wall sculpturing in xylem conduits. Journal of Bionic Engineering 6: 324-329.

Lens F, Dressler S, Jansen S, Van Evelghem L, Smets E. 2005. Relationships within balsaminoid Ericales: a wood anatomical approach. American Journal of Botany 92: 941-953.

Lens F, Endress ME, Baas P, Jansen S, Smets E. 2009. Vessel grouping patterns in subfamilies Apocynoideae and Periplocoideae confirm phylogenetic value of wood structure within Apocynaceae. American Journal of Botany 96: 2168-2183.

Lens F, Gasson P, Smets E, Jansen S. 2003. Comparative wood anatomy of epacrids (Styphelioideae, Ericaceae s.1.). Annals of Botany 91: 835856.

Lens F, Luteyn JL, Smets E, Jansen S. 2004. Ecological trends in the wood anatomy of Vaccinioideae (Ericaceae s.1.). Flora 199: 309-319.

Li YY, Sperry JS, Taneda H, Bush SE, Hacke UG. 2008. Evaluation of centrifugal methods for measuring xylem cavitation in conifers, diffuse and ring-porous angiosperms. New Phytologist 177: 558-568.

Loepfe L, Martinez-Vilalta J, Piñol J, Mencuccini M. 2007. The relevance of xylem network structure for plant hydraulic efficiency and safety. Journal of Theoretical Biology 247: 788-803.

Martínez-Cabrera HI, Jones CS, Espino S, Schenk HJ. 2009. Wood anatomy and wood density in shrubs: responses to varying aridity along transcontinental transects. American Journal of Botany 96: 1388-1398.

McDowell N, Pockman WT, Allen CD, Breshears DD, Cobb N, Kolb T, Plaut J, Sperry J, West A, Williams DG et al. 2008. Mechanisms of plant survival and mortality during drought: why do some plants survive while others succumb to drought? New Phytologist 178: 719-739.

Nijsse J. 2004. On the mechanism of xylem vessel length regulation. Plant Physiology 134: 32-34.

Ogata K. 1967. A systematic study of the genus Acer. Bulletin of the Tokyo University Forests 63: 89-206.

Onoda Y, Richards AE, Westoby M. 2009. The relationships between stem biomechanics and wood density is modified by rainfall in 32 Australian woody plant species. New Phytologist 185: 493-501.

Patterson R, Tanowitz BD. 1989. Evolutionary and geographical trends in adaptive wood anatomy in Eriastrum densifolium (Polemoniaceae). American Journal of Botany 76: 706-713.

Pittermann J, Choat B, Jansen S, Stuart SA, Lynn L, Dawson T. 2010. The relationships between xylem safety and hydraulic efficiency in the Cupressaceae: the evolution of pit membrane form and function. Plant Physiology 153: 1919-1931.

Pockman WT, Sperry JS, O'Leary JW. 1995. Sustained and significant negative water pressure in xylem. Nature (London) 378: 715-716.

Rasband WS. 1997-2004. ImageJ. Bethesda, MD, USA: National Institutes of Health [WWW document].URL http://rsb.info.nih.gov/ij/ [accessed on 1 October 2010]. 
New

Rood SB, Patino S, Coombs K, Tyree MT. 2000. Branch sacrifice: cavitation-associated drought adaptation of riparian cottonwoods. TreesStructure and Function 14: 248-257.

Rosell JA, Olson ME, Aguirre-Hernández R, Carlquist S. 2007. Logistic regression in comparative wood anatomy: tracheid types, wood anatomical terminology, and new inferences from the Carlquist and Hoekman southern Californian data set. Botanical Journal of the Linnean Society 154: 331-351.

Sperry JS, Hacke UG, Feild TS, Sano Y, Sikkema EH. 2007. Hydraulic consequences of vessel evolution in angiosperms. International Journal of Plant Sciences 168: 1127-1139.

Sperry JS, Hacke UW, Pittermann J. 2006. Size and function in conifer tracheids and angiosperm vessels. American Journal of Botany 93: 14901500.

Sperry JS, Tyree MT. 1988. Mechanism of water stress-induced xylem embolism. Plant Physiology 88: 581-587.
Taneda H, Sperry JS. 2008. A case study of water transport in cooccurring ring- versus diffuse-porous trees: contrasts in water-status, conducting capacity, cavitation and vessel refilling. Tree Physiology 28: $1641-1651$.

Tissier J, Lambs L, Peltier J-P, Marigo G. 2004. Relationships between hydraulic traits and habitat preference for six Acer species occurring in the French Alps. Annals of Forest Sciences 61: 81-86.

Wheeler JK, Sperry JS, Hacke UG, Hoang N. 2005. Intervessel pitting and cavitation in woody Rosaceae and other vesselled plants: a basis for a safety versus efficiency trade-off in xylem transport. Plant, Cell \& Environment 28: 800-812.

Yamauchi F. 1962. Anatomical identification of the woods in Japanese Acer. Miscellaneous Reports of the Research Institute for Natural Resources, Tokyo 58-59: 3-11.

Zimmermann MH. 1983. Xylem structure and the ascent of sap. Berlin, Germany: Springer-Verlag.

\section{About New Phytologist}

- New Phytologist is owned by a non-profit-making charitable trust dedicated to the promotion of plant science, facilitating projects from symposia to open access for our Tansley reviews. Complete information is available at www.newphytologist.org.

- Regular papers, Letters, Research reviews, Rapid reports and both Modelling/Theory and Methods papers are encouraged. We are committed to rapid processing, from online submission through to publication 'as-ready' via Early View - our average submission to decision time is just 29 days. Online-only colour is free, and essential print colour costs will be met if necessary. We also provide 25 offprints as well as a PDF for each article.

- For online summaries and ToC alerts, go to the website and click on 'Journal online'. You can take out a personal subscription to the journal for a fraction of the institutional price. Rates start at $£ 149$ in Europe/\$276 in the USA \& Canada for the online edition (click on 'Subscribe' at the website).

- If you have any questions, do get in touch with Central Office (newphytol@lancaster.ac.uk; tel +44 1524 594691) or, for a local contact in North America, the US Office (newphytol@ornl.gov; tel +1 865576 5261). 